\title{
Change in the air
}

\author{
Policy should pay closer attention to the increasing body of research on the links between energy, climate and health.
}

$\Lambda$ $t$ the end of April, Great Britain broke its record for the longest period of coal-free power generation ${ }^{1}$. The last record had been set less than a year before, in June 2019. Meanwhile, Sweden became the third European country to cease coal-powered electricity generation, two years earlier than planned ${ }^{2}$.

This is good news in terms of carbon emissions and air pollution reductions. Although the downturn in coal generation is part of a continuing trend in Great Britain, this latest coal-free spell was boosted by reduced demand during the COVID-19 lockdown combined with exceptional weather. Similar reductions have been seen in other regions around the world after lockdown measures came into effect. As economic activities resume, these reductions are unlikely to persist without some kind deliberate action or intervention. Such interventions can have co-benefits beyond just an acceleration of the transition towards achieving climate goals. The change in air quality - however temporary - should offer some pause for reflection on the impact of energy technology on health, for instance.

The link between air quality and health is now well-established ${ }^{3}$. Many governments are increasingly introducing measures and policies to reduce pollutants such as $\mathrm{PM}_{2.5}, \mathrm{SO}_{2}$ and $\mathrm{NO}_{x}$. Key sources of these pollutants include fossil fuel power generation technologies, vehicle emissions and - in homes - cooking and heating fuels. More and more research is exploring connections between these different energy technologies, policy implementation, and health and economic outcomes.

In one such study, outlined in an Article in this issue, Joan Casey and colleagues use a change in coal power generation to examine impacts on asthma sufferers in Louisville, Kentucky. Between 2012 and 2016, in response to regulations, one coal-powered plant was retired and three others installed scrubbers to reduce pollutants. The research team found that nearly 400 hospitalizations and emergency room visits were avoided annually as a result. Data obtained from sensors on inhalers also showed a $17 \%$ average decrease in monthly usage.

The impact of long-term exposure to air pollutants was also thrown into stark relief by a study that appeared on the medRxiv preprint server in April ${ }^{4}$. The analysis presented there found that exposure to $\mathrm{PM}_{2.5}$ was associated with an increase in COVID-19 mortality rate. While at the time of writing it had not been formally peer reviewed and published, the paper indicates a potential vulnerability of our modern societies to future epidemics of a similar nature - but also one that can and is being addressed, albeit indirectly.

Studies such as these two and many others should underscore the important and positive impacts of air pollution controls and regulation for society. And yet in the US where both these studies were conducted the Environmental Protection Agency just announced that it would not tighten current restrictions on the power sector ${ }^{5}$. The Agency has undertaken a series of measures under President Trump to relax Obama administration clean power regulations, despite evidence of their benefit to public health and the environment.

Different racial and socio-economic groups are affected differently by air pollution ${ }^{6}$. This inevitably compounds health and mortality impacts and raises important justice questions, irrespective of other climate or environmental goals. Research must continue to play a vital role in exposing injustices such as this and providing evidence for policies to address them. This will require government bodies to ramp up funding to investigate the intersection of air pollution, health and demographics - and then to follow that evidence.

Meanwhile, although less important in the Global North, indoor air pollution is a critical issue in many parts of the Global South ${ }^{7}$. The use of biomass for cooking remains a key contributor to this issue. In India, the Pradhan Mantri Ujjwala Yojana (PMUY) energy programme launched in 2016 as a route to provide access to liquified petroleum gas (LPG) to households that relied on solid fuels for cooking and heating. Subsidies and loans allowed households to obtain stoves and gas cylinders that they wouldn't otherwise be able to obtain.

A new survey of rural households from 2014-2015 and 2018 examines the drivers of LPG use under the scheme ${ }^{8}$. Sunil Mani, Saurabh Tripathi and colleagues find that, despite the enormous uptake of the programme, PMUY beneficiaries are less likely to use LPG as their primary or exclusive fuel than general LPG customers, even considering economic status. Odds of sustained use decrease with increasing cattle ownership and frequency of firewood collection, and increase with increasing income. The research team suggests that the PMUY programme could be further boosted by tying it in with other rural development policies aiming for instance at income growth. More targeted promotion at the village level and a greater convergence with other schemes would likely lead to a more sustained transition to cleaner cooking fuels and hence lower indoor air pollution and improved health.

An ever-growing body of evidence points to the benefits available across policy goals - energy, climate change, the environment, health, justice, economic development and more - by taking action in any of them. Indeed, recent modelling ${ }^{9}$ illustrates the 'no regrets' nature of coal phase outs in many parts of the world. Economic impacts of policy options should not be considered through a narrow lens focused only on the immediate system under scrutiny, while a host of exogenous factors go unaccounted for.

Published online: 20 May 2020

https://doi.org/10.1038/s41560-020-0630-9

\footnotetext{
References

1. Great Britain's new record for the longest period of coal-free electricity generation. National Grid ESO https://www. nationalgrideso.com/news/great-britains-new-recordlongest-period-coal-free-electricity-generation (2020).

2. Simon, F. Sweden adds name to growing list of coal-free states in Europe. Euractiv https://www.euractiv.com/section/energy/ news/sweden-adds-name-to-growing-list-of-coal-freestates-in-europe/2 (2020).

3. Landrigan, P. J. et al. Lancet 391, 462-512 (2017).

4. Wu. et al. Preprint at https://www.medrxiv.org/content/ 10.1101/2020.04.05.20054502v2 (2020).

5. Frazin, R. \& Beitsch, R. EPA issues rule critics say threatens power plant pollution regulation. The Hill https://thehill.com/ policy/energy-environment/493226-epa-issues-rule-criticssay-threatens-power-plant-pollution (2020).

6. Ard, K. Soc. Sci. Research 53, 375-390 (2015).

7. Burning Opportunity: Clean Household Energy for Health, Sustainable Development, and Wellbeing of Women and Children (WHO, 2016); https://apps.who.int/iris/bitstream/ handle/10665/204717/9789241565233_eng.pdf;jsessionid= C6B3ABE4CD2BDC015C5AEF6E63D2A6D4? sequence=1

8. Mani, S., Jain, A., Tripathi, S. \& Gould, C. F. Nat. Energy https:// doi.org/10.1038/s41560-020-0596-7 (2020).

9. Rauner, S. et al. Nat. Clim. Chang. 10, 308-312 (2020).
} 